\title{
A National Evaluation of State and Territory Roles in Hazard Mitigation: Building Local Capacity to Implement FEMA Hazard Mitigation Assistance Grants
}

\author{
Gavin Smith ${ }^{1, *}$ and Olivia Vila ${ }^{2}$ \\ 1 Department of Landscape Architecture and Environmental Planning College of Design, North Carolina State \\ University, Campus Box 7701, Raleigh, NC 27675, USA \\ 2 Department of Parks, Recreation and Tourism Management, North Carolina State University, 2820 Faucette \\ Drive, Raleigh, NC 27607, USA; ofvila@ncsu.edu \\ * Correspondence: gavin_smith@ncsu.edu
}

Received: 2 November 2020; Accepted: 27 November 2020; Published: 30 November 2020

check for updates

\begin{abstract}
This article describes the findings of a national survey of State Hazard Mitigation Officers (SHMOs) in U.S. states and territories in order to gain a greater understanding of the roles that they play in assisting local governments to build the capacity required to successfully develop and implement Federal Emergency Management Agency (FEMA)-funded Hazard Mitigation Assistance (HMA) grants, an important but understudied aspect of hazard mitigation governance. The research questions focus on: (1) How states and territories enable local governments to develop and implement HMA grants and (2) SHMOs' opinions regarding their perceived capacity and effectiveness in assisting local governments to develop and implement HMA grants. Results show that while states and territories are relatively well-equipped to perform general administrative duties required by FEMA, SHMOs expressed wide variation in their capacity to assist local governments to develop and implement HMA grants. This was particularly evident with regard to the delivery of specific technical assistance measures required to develop HMA grants. Survey responses also highlight modest levels of participation in FEMA-designed efforts to delegate responsibility to states and territories and low levels of participation in programs that offer pre-application funding to local governments to help them develop HMA grant applications. These findings should concern FEMA as the agency embarks on the implementation of the Building Resilient Infrastructure and Communities program, an ambitious pre-disaster hazard mitigation grant initiative.
\end{abstract}

Keywords: hazard mitigation assistance grants; state hazard mitigation officer; local capacity building

\section{Introduction}

Disaster-related losses in the United States have risen exponentially over the last several decades and this trend is expected to accelerate due to the compounding effects of climate change and continued growth in hazard-prone areas [1-3]. In 2017, disaster losses exceeded 309.5 billion dollars in the United States, resulting in the costliest year ever recorded [4]. According to the National Oceanic and Atmospheric Administration (NOAA), there were 16 climate and weather-related disasters in 2020 that exceeded 1 billion dollars. Since 1980, where overall damages reached or exceeded 1 billion dollars (controlling for inflation), the total cost of these 279 events exceeded 1.825 trillion dollars [5].

These statistics point to the importance of taking action before and after disasters to stem or at least reduce the trajectory of future losses. In the United States, such actions are referred to as hazard mitigation, which FEMA defines as " ... any sustainable action that reduces or eliminates long-term 
risk to people and property from future disasters" [6]. The implementation of FEMA-provided hazard mitigation grants often supports a larger risk reduction strategy employed by communities [7-10], including actions intended to adapt to climate-change induced or exacerbated natural hazards and disasters [11-13].

Research shows that Federal Emergency Management Agency (FEMA)-funded Hazard Mitigation Assistance (HMA) grants can pay significant dividends in terms of future losses avoided, equating to a nationwide average of four to one or greater return on investment [14]. However, the administration of HMA grants are often fraught by high program complexity, significant data requirements, and difficulty in obtaining access to financial resources and technical expertise, leading to lengthy project development and implementation timelines and an uneven distribution of assistance [15-24].

While states and territories serve as an important intermediary between federal funding and project development and implementation at the municipal and county level, there is limited research on the role that states play in the HMA administrative process [25-27]. As part of the special Issue entitled "Planning Resilient Community: Public Participation and Governance," this article addresses an important but less understood aspect of governance and resilience: the state-local relationship, emphasizing the role of states and territories as a hazard mitigation grant management capacity builder.

FEMA, which provides a series of pre- and post-disaster hazard mitigation grants (collectively known as Hazard Mitigation Assistance or HMA), passes funds through states and territories, which serve as the recipient. States and territories establish prioritization policies which inform how the federal hazard mitigation funds will be allocated at the local level, while adhering to federally-mandated eligibility requirements, such as cost-effectiveness, the technical feasibility of projects, and environmental considerations [9]. States and territories also lead capacity-building initiatives to help local governments develop and implement hazard mitigation grants [25], which they submit to states and territories as sub-recipients. While these sub-national governments play an important intermediary role in the vertical integration of federal funding and local implementation of hazard mitigation grants and associated projects, the understanding of how this process functions and the effectiveness of states and territories in building the capacity of local governments to develop and implement HMA grants remains less understood by researchers and practitioners [25,28,29].

State Hazard Mitigation Officers (SHMOs) are the primary administrative officials in U.S. states and territories assigned to manage FEMA hazard mitigation grants. Specific duties include: ensuring local compliance with HMA rules, the development of prioritization strategies for the distribution of HMA funds in their respective state or territory, the development of state or territory hazard mitigation plans in which HMA funding strategies are located, and building the capacity of local governments to apply for and implement HMA grants [25]. The responses of SHMOs to a national survey provide the primary source of data in this article, which seeks to improve our understanding of the roles states and territories play in hazard mitigation grant management. The research questions addressed in this article include:

- How do states and territories enable local governments to develop and implement HMA grants?

- What are SHMOs' perceived capacity and effectiveness in assisting local governments to develop and implement HMA grants?

In order to provide relevant context and background, an overview of HMA grant management policy, including national legislation and the role of states and territories in managing these programs, is discussed next. The methods, including survey design, research population, recruitment strategy, and limitations of the data, are then described. The survey results are then analyzed and discussed. Conclusions, policy recommendations, and future research wrap up the article. 


\section{Overview of Hazard Mitigation Assistance Policy}

The evolution of the HMA grant management policy can be traced to three primary pieces of legislation, including the Robert T. Stafford Act (1988), the Disaster Mitigation Act of 2000, and the Disaster Recovery Reform Act (2018). The Stafford Act consolidated several federal disaster recovery programs in one agency (FEMA) while adding a dedicated source of post-disaster hazard mitigation funding - the Hazard Mitigation Grant Program (HMGP). Funding for the HMGP is triggered by a federally declared disaster, whereby the equivalent of 15 percent of federal disaster costs is provided to states and territories through the program. States and territories establish hazard mitigation priorities and pass this funding on to local governments to implement hazard mitigation projects. Examples of hazard mitigation projects funded through the HMGP and other HMA programs include the acquisition and demolition of hazard-prone housing (and conversion of the property to open space), the retrofitting or strengthening of buildings and infrastructure to better withstand hazard forces, stormwater management, and hazard mitigation planning. FEMA also manages the Flood Mitigation Assistance Program (FMA), which focuses on funding risk reduction measures targeting repetitively flooded National Flood Insurance Program (NFIP)-insured housing and businesses.

The Disaster Mitigation Act of 2000 was intended to address several long-standing problems tied to hazard mitigation policy, including grants administration. These included: (1) reduce escalating disaster costs through the development of pre-disaster state and local hazard mitigation plans; (2) speed the implementation of HMGP-funded projects, thereby reducing large unspent balances; and (3) provide pre-disaster hazard mitigation funds to support more proactive risk reduction efforts [30] (pp. 106-139). Achieving the first two aims of the DMA remains unrealized, in part, because insufficient attention has been placed on local capacity building efforts led by state officials to improve the application of land use planning practices and grant management techniques [31] (pp. 283-284) [24,25,32].

The DMA requires that states and local governments must develop pre-disaster hazard mitigation plans to remain eligible for pre- and post-disaster hazard mitigation grant funding. The original intent of these plans was to pre-identify possible hazard mitigation projects, thereby speeding the expenditure of post-disaster hazard mitigation funds and limiting future development in known hazardous areas through the application of appropriate land use measures. While local plans meet the minimal standards established by FEMA, most plans do not pre-identify projects nor comprehensively apply land use measures to reduce risk [31] (p. 292) [33,34]. State hazard mitigation plans tend to emphasize a listing of federal grant programs rather than developing a more robust and comprehensive risk reduction strategy, to include building and sustaining local capacity [25].

Another key component of the DMA is the Pre-Disaster Mitigation Program (PDM), which supports a more proactive approach to hazard mitigation funding, in contrast to the HMGP, which is only available to states and territories following a federally-declared disaster. The PDM grant application and funding process is similar to HMGP and other HMA grant programs, as shown in Figure 1. While the PDM program has been widely lauded by researchers and practitioners, critics point out that the majority of funding is part of a nationally competitive process, which may hinder the ability of communities with fewer resources and less internal capacity to develop a "winning" proposal [35] (pp. 65-66). 


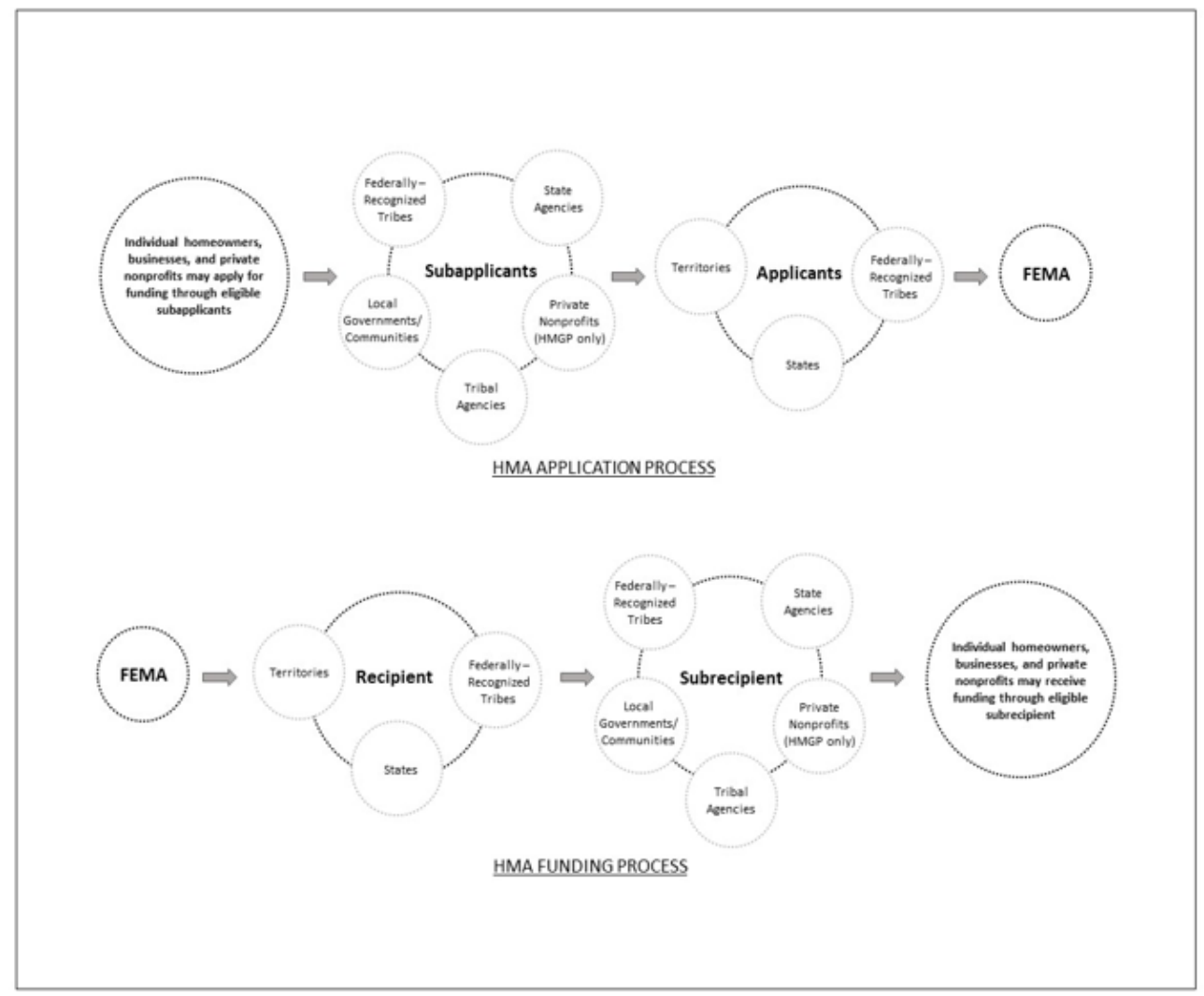

Figure 1. Federal Emergency Management Agency (FEMA) Hazard Mitigation Assistance (HMA) application and funding process. Adapted from content found in FEMA's HMA guidance [9] (p. 81).

In 2018, Congress passed the Disaster Recovery Reform Act (DRRA), which amends key parts of the DMA through the creation of the pre-disaster Building Resilient Infrastructure and Communities (BRIC) grant program. BRIC, which replaced PDM, is based on a pre-disaster allocation strategy that equates to six percent of the previous year's total disaster losses across the United States. When applied to the 2020-2021 funding cycle, the BRIC allocation formula to states and local governments equates to approximately 500 million dollars [36]. Unlike the new BRIC funding allocation strategy, PDM funding was based on annual congressionally appropriated budgets, which were subject to variation in any given year. While BRIC program funds are based on a prior year's disaster losses, in an era of climate change and continued development in high-hazard areas, it is likely that these funds will continue to rise over time.

\section{Materials and Methods}

In this section, the survey design, including the process used to create it and the nature of the questions is discussed. A brief description of survey response rates and the recruitment strategy follows. A discussion of survey limitations, including the gaps among prospective participants concludes the methods section.

\subsection{Survey Design}

The Qualtrics-based online survey was developed at the request of FEMA officials responsible for the administration of national HMA policy, including BRIC [37]. A team of North Carolina State University researchers, in collaboration with FEMA personnel and their contractors created the survey. Following the completion of a draft survey, the protocol was pilot tested by researchers and a former SHMO to assess content accuracy, survey length, and the ordering of questions. Question ordering followed the suggestions of [38] to include question complexity, importance, grouping across common 
themes or content, flow, and continuity. Likert scale, multiple-answer, multiple choice, and ranking questions served as the primary means to elicit information. Open-ended questions were used sparingly when more detail was desired. Conditional branching was used in the survey design, meaning that specific questions varied based on responses to prior questions.

\subsection{Research Population and Recruitment}

Our study population includes 56 SHMOs, drawing from each state, the District of Columbia, and five U.S. territories. In total, $43 \mathrm{SHMOs}$ responded to the survey, resulting in a response rate of $77 \%$. Respondents varied in terms of their tenure in the job, ranging from two months to 15 years. Of the 43 respondents, 6 reported that they were not the SHMO, but rather an individual designated by the SHMO to answer the survey as they were responsible for HMA grants administration. Five SHMOs indicated that they assumed additional duties such as grants manager, state long term recovery task force lead, and mitigation branch manager. A couple of SHMOs noted that they worked in a closely related position such as a mitigation specialist or hazard mitigation planner prior to promotion.

Recruitment efforts involved contacting the SHMOs via their publicly available work email and utilizing a script to explain the nature of the research project. If SHMOs expressed a willingness to participate, the survey link was emailed to them. Follow-up emails and phone calls were used if participants did not respond to the initial recruitment. Participants were required to give their informed consent prior to sending them the survey protocol.

\subsection{Survey Limitations and Modifications}

The survey was intended to query state, territory, and tribal representatives responsible for the administration of HMA grants. One factor that likely impacted survey response rates was the COVID-19 pandemic, as many SHMOs have been tasked with assisting their respective agencies to address issues beyond their normal day-to-day activities, to include working in their Emergency Operations Center, assisting with logistics or other tasks as assigned. In addition, the research team was unable to obtain a list of tribal representatives and as a result, they were not included in this survey, nor was there a high response rate among U.S. territories, as only one of six possible SHMOs completed the survey. The latter examples negate the ability of the survey to capture responses from some of the country's most resource-poor locations, and as such, this limits the understanding of these entities' ability to assist their respective jurisdictions to apply for and administer HMA grants. Given these limitations, the overall findings likely overestimate the nationally aggregated capacity of SHMOs to assist local governments.

\section{Results and Discussion}

First, the percentage of states and territories administering HMGP, PDM, and FMA at the time the survey was administered are described. Next, the programs and resources used to promote the development and implementation of HMA grants to include Management Costs, Program Administration by States, and Advanced Assistance are discussed. Then, the perceived capacity of SHMOs to assist in the building of local HMA grant management capacity is assessed, followed by a review of how SHMOs perceive the effectiveness of their efforts.

\subsection{HMA Program Participation among Survey Respondents}

In order to gain a better picture of HMA program participation in each state and territory, SHMOs were asked to report whether they received HMA funding in the last fiscal year. At the time of the survey, all states and territories were eligible recipients of all HMA programs, which includes the Hazard Mitigation Grant Program (HMGP), the Pre-Disaster Mitigation Grant Program (PDM), and the Flood Mitigation Assistance Program (FMA). Among those surveyed, most indicated that they were administering HMGP (91\%) and PDM (86\%), while a little under half indicated that they were 
administering FMA (44\%). While most states and territories participated in at least two programs $(84 \%)$, a small number participated in a single program $(16 \%)$.

\subsection{Programs and Resources for Promoting the Development and Implementation of HMA Grants}

States and territories can draw from several programs to bolster their capacity to assist local governments to develop and implement HMA grants. Survey questions focused on the following federal and state efforts: Program Administration by States (PAS), Advanced Assistance (AA), post-disaster based HMGP management costs, and resources provided by states and territories.

\subsection{FEMA's Program Administration by States and Advance Assistance Program}

In an effort to improve the timely development and implementation of HMA grants, FEMA created the PAS and AA programs. PAS allows FEMA to delegate some of its traditional grant management responsibilities to states, territories, and federally recognized tribes. These responsibilities include (but are not limited to): reviewing project applications, completing benefit-cost analyses (BCA) for projects, approving scope-of-work modifications, moving funds between applicable projects, and the review and approval of hazard mitigation plans.

The survey results reveal that the PAS program is not widely used among states and territories (Table 1). Sixty-seven percent of the respondents indicated that their state or territory was not currently participating in the program. The most commonly cited reasons for non-participation included limited state capacity and the absence of incentives to participate, where $79 \%$ and $62 \%$ of the SHMOs indicated that they "strongly agree" or "somewhat agree" with those reasons. This suggests a compounded problem for FEMA in that most states and territories not only feel that the additional PAS responsibilities exceed their abilities, SHMOs also stated that they derive little benefits by taking on these additional tasks.

Table 1. Reported participation in the Program Administration by States (PAS) and Advanced Assistance (AA) programs.

\begin{tabular}{cc}
\hline Question & Percent (n) \\
\hline Does the Jurisdiction You Represent Currently Participate in PAS? (n = 43) & \\
\hline Nos & $16.3(7)$ \\
Not sure & $67.4(29)$ \\
Funding? (n= 43) & $16.3(7)$ \\
\hline Yes & \\
No & $81.4(35)$ \\
Not sure & $18.6(8)$ \\
Has the jurisdiction you represent ever applied for FEMA's Advance Assistance & $0(0)$ \\
\hline Has the jurisdiction you represent ever received FEMA's Advance Assistance Funding? & \\
(n= 35) & $65.1(28)$ \\
Yes & $27.9(4)$ \\
No & $7.0(3)$ \\
\hline
\end{tabular}

Sixteen percent of survey participants indicated that they were not sure if their state or territory was currently participating, highlighting a potential lack of clarity about the program or perhaps a lack of knowledge transfer from SHMOs who previously held the position (several SHMOs noted a relatively short job tenure, which may limit their capacity to aid local governments due to their lack of knowledge and experience). Of the respondents who said that their state or territory had participated in the program, most indicated using the PAS program to review and approve hazard mitigation plans and review project applications. Slightly less common was the use of the PAS program 
to review and approve BCA analyses, approve scope of work modifications, and move funds between applicable projects.

Of the 36 respondents who indicated that their state or territory was not currently participating in PAS, or were not sure if their state or territory was participating in the program, they were asked to describe the likelihood that they would use PAS in the future to address certain activities. Similar to those jurisdictions which currently participate in PAS, respondents appeared interested in taking on the responsibilities for reviewing project applications and reviewing and approving hazard mitigation plans, where $89 \%$ and $63 \%$ respectively, indicated that they would "definitely" or "probably" take on those particular roles. Respondents also indicated a strong interest (definitely or probably) in the other activities, such as reviewing and approving BCA analyses (71\%), approving scope of work modifications $(80 \%)$, and moving funds between applicable projects $(74 \%)$. Together, these findings seem to indicate a need to better align the provision of FEMA assistance programs with state needs and capabilities, to include efforts that align with prior research documenting the mismatch between federal program requirements and state capacity [25]. More specifically, this may require more targeted state- and territory-focused capacity building strategies coupled with more appropriate incentives that resonate with SHMOs.

As part of the Sandy Recovery and Improvement Act of 2013, FEMA was authorized to create the AA program, which is intended to assist local governments develop an HMGP application when they may not possess the resources to do so otherwise. AA funds can be used by local governments to develop hazard mitigation strategies and obtain data to prioritize, select, and develop HMGP applications in a timely manner. Sixty-five percent of SHMOs indicated that local governments in their state or territory had applied for and successfully received AA funding, while $19 \%$ reported that local governments in their state or territory had never applied. It is important to note that SHMOs were asked whether any local government in their state or territory had applied for AA funds. As a result, it is unclear how many counties or municipalities have actually sought out this type of assistance in those states and territories where respondents affirmatively answered the question. It also remains uncertain as to the makeup of local governments who did not apply for AA funding relative to their capacity to write an HMA application.

Of the eight respondents who said that no local jurisdiction in their state or territory had ever applied, there did not appear to be an overwhelmingly consistent reason tied to their nonparticipation, although four respondents noted that they "somewhat agreed" with the statement that there was both an unclear understanding of the program and that eligible activities did not meet local needs. While this represents a small number of respondents from which to draw conclusions, the results suggest that additional research should be undertaken to further explore accessibility to AA funding, including jurisdictions who chose not to participate but are located in states and territories where other jurisdictions have pursued this type of assistance.

Of the $65 \%$ of SHMOs who indicated that they had local governments in their states and territories who had previously participated in the AA program, most indicated that local governments used the Advance Assistance program for addressing data consistency needs, potentially highlighting nation-wide data limitations, which have been previously documented in the literature [39]. According to respondents, local governments also used Advance Assistance funding for engineering studies, identifying potential match funding, and performing cost-estimation services. AA funds were less commonly used to develop hazard mitigation project applications, evaluate facilities to determine mitigation actions, or complete necessary documents for deed restricting land following the acquisition and demolition of flood-prone properties.

The SHMOs who indicated that local governments in their state or territory had either not participated in AA or were not sure if they had successfully received AA funding were asked to describe the perceived likelihood that local governments would use Advance Assistance in the future. These data somewhat contrast with the way Advance Assistance has been used previously, and according to SHMOs, local governments may be interested in using Advance Assistance less 
for addressing data limitations, and more to develop hazard mitigation project applications. These findings could serve to inform the future actions of SHMOs to include the targeted use of management costs or state appropriated resources to address needs among local governments that are not being met through the AA program.

\subsection{Management Costs}

One of the primary funding vehicles used by states and territories to support the administration of post-disaster based HMGP funds, including grant management and local capacity building initiatives, are FEMA-provided management costs, which equate to no more than $15 \%$ of the total HMGP award [40]. The provision of management costs, as promulgated under the Stafford Act, stems from the large sums of grant money available to states and territories following federally-declared disasters and the related need to supplement the capacity of SHMOs and their staff members. In the case of large disasters, such as Hurricane Maria, the total HMGP funds provided to states and territories can equate to several billion dollars.

When asked about the ways their state or territory uses their management cost funding, SHMOs noted that they frequently used the funds to hire staff to help address the significant burden associated with the HMGP grant management administration (Table 2). As noted in prior studies, the disaster-based hiring of state-level staff can lead to significant fluctuations in capacity over time [19,25]. Management costs were also used to hire consultants, as almost half of those queried stated that the funds were used for this purpose. This appears to align with a multi-decadal trend of hiring contractors to assume state and territorial hazard mitigation and disaster recovery responsibilities [35] (pp. 159, 164-166) [41,42]. While the hiring of temporary staff and contractors is widely used to bolster grant management capacity, it has the potential to limit the transfer of lessons to future HMA grant administrators, unless state and territorial officials work closely with temporary staff and contractors to capture and archive this information [35] (p. 165).

Table 2. Reported use of management costs.

\begin{tabular}{ccc}
\hline Question & Percent (n) \\
\cline { 1 - 2 } How Does Your State or Territory Use Their Management Costs? (n = 43) & \\
\hline Hire permanent state staff. & $74.4(32)$ \\
Hire temporary state staff. & $58.1(25)$ \\
Hire consultants. & $48.8(21)$ \\
Conduct training. & $83.7(36)$ \\
Collect and analyze data. & $51.2(22)$ \\
Develop manuals, guides, etc. & $60.5(26)$ \\
Conduct local risk assessments. & $32.6(14)$ \\
Conduct local engineering studies. & $9.3(4)$ \\
Provide legal assistance. & $7.0(3)$ \\
Write local grant applications. & $34.9(15)$ \\
Implement local grant applications. & $44.2(19)$ \\
Create quarterly reports. & $86.0(37)$ \\
Provide payment reimbursements. & $74.4(32)$ \\
Conduct project closeouts. & $88.4(38)$ \\
Conduct Environmental Planning and Historic Preservation (EHP) review. & $30.2(13)$ \\
Prepare Benefit-Cost Analysis. & $67.4(29)$ \\
\hline
\end{tabular}

According to SHMOs, capacity building tasks were also widely undertaken using management costs to conduct training and develop manuals and guides. In addition, states and territories undertook a range of activities that are typically assumed to be part of the responsibilities of local government grant applicants, such as collecting and analyzing data, conducting local risk assessments, preparing benefit-cost analyses, conducting environmental and historic preservation reviews, and even writing and implementing local grant applications. Among the highest responses of state and territorial 
officials were tied to specific financial management activities, such as creating quarterly reports for FEMA, approving applicant reimbursements, and conducting project closeout procedures once the grant was completed. However, conducting local engineering studies and providing legal assistance were noticeably less likely to occur.

The results suggest that while states and territories undertook a range of activities using management costs, SHMOs placed the greatest emphasis on administrative- and outreach-related duties and less on those activities that are traditionally assumed by local governments (with the exception of conducting benefit-cost analyses). This makes sense, as many states and territories maintain a small HMA grant management cadre, unless they are able to staff up following a major disaster declaration, although some states and territories are precluded from hiring temporary state personnel [25].

\subsection{Resources Provided by States and Territories}

States and territories also provide resources to assist local governments, as highlighted in Table 3. When asked about the frequency with which state or territorial resources were used to provide guidance on grant application development, states and territories responded that they "always" (45\%) or "often" $(31 \%)$ provided resources to assist with this phase of grant management, to include the creation of manuals, guides, and training programs. Similar responses were found when SHMOs were questioned about providing assistance with grant implementation. However, when assessed relative to the general responsibilities of SHMOs described earlier in this article, these numbers seem relatively low, given that these tasks are recognized roles that should be assumed by all states and territories.

A combined $28 \%$ of respondents noted that they "never" $(5 \%)$ or "rarely" $(23 \%)$ provide the resources to build local skills and knowledge around how to effectively coordinate with other local jurisdictions. The relatively high number of SHMOs reporting that they did not engage in this type of effort conflicts with widespread hazard mitigation scholarship and practice-based guides that emphasize the importance of good governance or what FEMA and many state and territory emergency management agencies refer to as the "whole community" approach when it comes to risk reduction endeavors. When asked a similar question about whether resources were provided by states and territories to facilitate building and sustaining partnerships through the use of manuals, templates, meetings, training, and communications platforms, respondents stated that these techniques were "sometimes" $(28 \%)$ or "often" $(28 \%)$ provided, while $19 \%$ and $5 \%$ said they were "rarely" or "never" provided, respectively. The relatively high number of SHMOs who said that helping local governments build necessary partnerships is not offered by states and territories has the potential to disproportionately impact smaller communities, as they are often reliant on external assistance provided by counties, regional planning organizations, university faculty, non-profits, and other organizations [35].

The documentation of best practices highlighting effective grant management activities represents another form of information sharing. Yet when SHMOs were queried about how often they provided case studies or summaries of local hazard mitigation projects in their state or territory, a high number of respondents noted that this was not a common practice. While FEMA generates these types of reports as part of a national effort or for states and territories post-disaster (perhaps part of the reason for the low response rates), the results appear to suggest a gap in capacity building via information sharing. A Government Accountability Office Report found that similar to states, FEMA does a poor job of capturing, archiving, and sharing post-disaster lessons both within its agency and with states and local governments [43]. 
Table 3. Resources provided by states and territories.

\begin{tabular}{|c|c|c|c|c|c|}
\hline Questions & & & & & \\
\hline $\begin{array}{l}\text { The Frequency with Which the } \\
\text { Jurisdiction You Represent Provides } \\
\text { the Following Types of Assistance at } \\
\text { the Local Level. }(\mathrm{n}=42) \text {. }\end{array}$ & $\%$ Always & $\%$ Often & $\%$ Sometimes & \% Rarely & $\%$ Never \\
\hline $\begin{array}{l}\text { Resources developed by the state or } \\
\text { territory that provide guidance on grant } \\
\text { application development. }\end{array}$ & 45.2 & 31.0 & 21.4 & 2.4 & 0 \\
\hline $\begin{array}{l}\text { Resources developed by the state, } \\
\text { territory, or tribe that provide guidance } \\
\text { on grant application implementation. }\end{array}$ & 45.2 & 33.3 & 19.0 & 2.4 & 0 \\
\hline $\begin{array}{l}\text { Resources to build local skills and } \\
\text { knowledge around embedding hazard } \\
\text { mitigation projects in local mitigation } \\
\text { plans. }\end{array}$ & 21.4 & 47.6 & 23.8 & 31.0 & 0 \\
\hline $\begin{array}{l}\text { Resources to build local skills and } \\
\text { knowledge around meeting FEMA } \\
\text { requirements or writing and } \\
\text { implementing FEMA grant } \\
\text { applications. }\end{array}$ & 38.1 & 31.0 & 31.0 & 0 & 0 \\
\hline $\begin{array}{l}\text { Resources to build local skills and } \\
\text { knowledge around how to effectively } \\
\text { coordinate with other local } \\
\text { jurisdictions. }\end{array}$ & 14.3 & 40.5 & 16.7 & 23.8 & 4.8 \\
\hline $\begin{array}{l}\text { Resources to facilitate building and } \\
\text { sustaining partnerships. }\end{array}$ & 19.0 & 28.6 & 28.6 & 19.0 & 4.8 \\
\hline $\begin{array}{l}\text { Case studies or summaries of local } \\
\text { hazard mitigation projects in your state, } \\
\text { territory, or tribe that highlight best } \\
\text { practices. }\end{array}$ & 19.5 & 26.8 & 19.5 & 26.8 & 7.3 \\
\hline Risk assessment training. & 7.1 & 16.7 & 28.6 & 31.0 & 16.7 \\
\hline Benefit-Cost Analysis training. & 16.7 & 19.0 & 33.3 & 31.0 & 0 \\
\hline $\begin{array}{l}\text { Data for use in local hazard mitigation } \\
\text { projects (e.g., climatic, geological data, } \\
\text { flood loss data). }\end{array}$ & 16.7 & 40.5 & 28.6 & 11.9 & 2.4 \\
\hline $\begin{array}{l}\text { Data or information about potential } \\
\text { funding sources. }\end{array}$ & 21.4 & 57.1 & 14.3 & 7.1 & 0 \\
\hline $\begin{array}{l}\text { Direct assistance with Benefit-Cost } \\
\text { Analysis. }\end{array}$ & 28.6 & 35.7 & 19.0 & 9.5 & 7.1 \\
\hline $\begin{array}{l}\text { Direct assistance writing hazard } \\
\text { mitigation grants. }\end{array}$ & 35.7 & 33.3 & 19.0 & 7.1 & 4.8 \\
\hline $\begin{array}{l}\text { Direct assistance implementing hazard } \\
\text { mitigation grants. }\end{array}$ & 38.1 & 28.6 & 19.0 & 14.3 & 0 \\
\hline $\begin{array}{l}\text { Direct assistance with grants } \\
\text { administration. }\end{array}$ & 33.3 & 26.2 & 21.4 & 14.3 & 4.8 \\
\hline Direct assistance with project scoping. & 14.6 & 48.8 & 26.8 & 7.3 & 2.4 \\
\hline $\begin{array}{l}\text { Direct assistance with engineering } \\
\text { studies and design. }\end{array}$ & 2.4 & 16.7 & 23.8 & 33.3 & 23.8 \\
\hline $\begin{array}{l}\text { Legal guidance on grant program } \\
\text { topics. }\end{array}$ & 7.1 & 14.3 & 28.6 & 23.8 & 26.2 \\
\hline $\begin{array}{l}\text { Pre-review of local hazard mitigation } \\
\text { projects. }\end{array}$ & 52.4 & 26.2 & 21.4 & 0 & 0 \\
\hline
\end{tabular}

Another indicator of state capacity that seems to highlight a bifurcation in those states and territories who do and do not provide a particular type of assistance is benefit-cost analysis. When queried about whether states or territories delivered benefit cost analysis training, $64 \%$ of respondents noted that this 
task was "rarely" (31\%) or "sometimes" (33\%) provided, even though $67 \%$ of respondents said they used FEMA-provided management cost funding to prepare benefit cost analysis for local governments. These seemingly conflicting responses may reflect that many states and territories do not conduct the actual training of local government officials and may defer to FEMA or their contractors to perform BCA training, whereas SHMOs may be more willing to conduct the actual BCA analysis for local governments when necessary following a federally-declared disaster (which triggers the release of HMGP funding and associated management costs to hire additional state and territory staff).

When asked about providing more general data, to include in local hazard mitigation projects (e.g., climatic, geological, flood losses), states and territories responded more affirmatively, with only $14 \%$ of respondents reporting that they "rarely" provided these types of data to local governments. The widespread sharing of this type of information may be due to the presence of datasets regularly managed by various state agencies to include the state or territory NFIP Coordinator, geologic survey, or department of environment and natural resources. When asked about the provision of information tied to potential funding sources, $57 \%$ of respondents noted that they "often" did so, while $21 \%$ responded that they "always" provided these resources. While none reported that they "never" provided this type of assistance, $21 \%$ of SHMOs said that they "sometimes" $(14 \%)$ or "rarely" $(7 \%)$ shared funding sources with local governments. Of those who responded non-affirmatively, this may be due to an assumption among SHMOs that the prospective funding to be provided through HMA grants adequately addresses local needs rather than recognizing that many successful hazard mitigation projects involve multiple sources of funding, including those that are not provided by FEMA, such as federal and state agencies, non-profits, and local municipal finances [44,45].

When asked whether states and territories provided direct assistance with writing and implementing hazard mitigation grants, SHMOs responded similarly, noting that they "often" or "always" do so (69\% and 66\%, respectively). Yet when queried about providing direct assistance with engineering studies and design, states and territories responded much less affirmatively. This suggests that states and territories appear more comfortable providing general administrative and financial guidance tied to the tracking and closeout of HMA grants and may be less adept at the provision of more technical assistance such as engineering-based analyses. While states and territories may emphasize general administrative support, most HMA grants have remained slow to implement, often taking years to complete, even after the passage of the DMA in 2000, which sought to speed up the grant management process. A study conducted by the Natural Resources Defense Council, which reviewed approximately 30 years of FEMA data, found that the median time required to complete hazard mitigation projects exceeded five years [22].

\subsection{Preceived State and Territorial Capacity to Assist Local Governments with HMA Grant Administation}

A series of questions posed to SHMOs provides insights into how they perceive the capacity of their state or territory to assist local governments to administer HMA grants (Table 4). When asked about whether they believed that their state or territory possessed the level of capacity (i.e., knowledge, skills, and abilities) required to assist local governments with HMA grant management activities, over $92 \%$ of SHMOs "strongly agreed or "somewhat agreed." Only $5 \%$ of respondents "somewhat disagreed," while $2 \%$ expressed a neutral opinion. Similar sentiments were voiced in a prior study involving six states, where SHMOs described what they believed to be strong state-level capacity building programs, while lamenting how low capacity communities did not take advantage of the available assistance [25].

Respondents were also asked about their capacity to assist local governments with their planning, regulatory, administrative, financial, and educational/outreach needs. The majority (64\%) of SHMOs strongly believe that their state or territory possesses the ability to assist local governments with their hazard mitigation planning needs. When questioned about their perceived capacity to assist local governments to address regulatory issues, almost $20 \%$ expressed reservations about having the resources required. 
Table 4. Reported capabilities of state or territory to help local governments with hazard mitigation needs.

\begin{tabular}{|c|c|c|c|c|c|}
\hline Question & & & $\%$ & & \\
\hline $\begin{array}{l}\text { Capabilities of the State or Territory to } \\
\text { Help Local Governments with Hazard } \\
\text { Mitigation Needs }(n=42) .\end{array}$ & $\begin{array}{c}\text { Strongly } \\
\text { Agree }\end{array}$ & $\begin{array}{l}\text { Somewhat } \\
\text { Agree }\end{array}$ & $\begin{array}{l}\text { Neither } \\
\text { Agree nor } \\
\text { Disagree }\end{array}$ & $\begin{array}{l}\text { Somewhat } \\
\text { Disagree }\end{array}$ & $\begin{array}{l}\text { Strongly } \\
\text { Disagree }\end{array}$ \\
\hline Hazard mitigation needs (general). & 59.5 & 33.3 & 2.4 & 4.8 & 0 \\
\hline Planning needs. & 64.3 & 23.8 & 4.8 & 7.1 & 0 \\
\hline Regulatory needs. & 28.6 & 45.2 & 7.1 & 14.3 & 4.8 \\
\hline Administrative needs. & 31.0 & 42.8 & 11.9 & 9.5 & 4.8 \\
\hline Financial needs. & 23.8 & 26.2 & 26.2 & 19.0 & 4.8 \\
\hline Education and outreach needs. & 40.4 & 35.7 & 14.3 & 4.8 & 4.8 \\
\hline
\end{tabular}

The perceived level of state and territory capacity to assist with local administrative needs was strongly affirmative, in that $31 \%$ "strongly agreed" and $42 \%$ somewhat agreed when questioned. Results were more evenly dispersed in relation to the provision of financial assistance. When SHMOs were asked about whether they believed that states and territories possessed the knowledge, skills, and resources required to deliver educational materials, 35\% "somewhat agreed" and 40\% of respondents "strongly agreed." It remains unclear if these numbers, which appear higher than the responses reported earlier when questioned about the development of documents addressing partnerships and case studies, for instance, represent the sharing of FEMA training materials or if states and territories developed their own, more targeted state- or territory-specific guidance and educational materials.

\subsection{Perceived State and Territorial Effectiveness}

Next, SHMOs were asked about the perceived effectiveness of their states and territories efforts to deliver 13 different capacity building activities to local governments (Table 5). When SHMOs were questioned about the perceived effectiveness of their ability to conduct benefit cost analysis for local HMA applicants, more than half of respondents (57\%) noted that they were either "somewhat effective" (31\%), "slightly effective" (19\%), or "not effective at all" (7\%). Given the complexity of FEMA's benefit-cost software and its data-intensive nature, the modest ability of states and territories to assist with this task does not bode well for local governments who are even less likely to possess this capability, unless they can afford to hire consultants to perform this activity.

The perceived ability of SHMOs to provide engineering expertise was even lower, with $74 \%$ stating that they were either "not effective at all" (37\%) or "slightly effective" (37\%). Less than 5\% stated that their state or territory was "extremely effective" in providing engineering expertise to assist local governments. Engineering expertise may be required, for instance, to conduct hydraulic analyses of proposed stormwater management projects or determine the loading capacity of varied infrastructures to external stressors such as wind, ground motion, or storm surges. Given the emphasis of the new Building Resilient Infrastructure and Communities (BRIC) program on the retrofitting of existing infrastructure and the funding of gray and green infrastructure projects, this will require an increased capacity of states, territories, and local governments to apply engineering practices during the grant writing process. Similar to the delivery of BCA training, local consultants may be expected to fill the void, which predisposes wealthier communities to hire firms as part of their larger grant management strategy, whereas poorer communities may be less likely to develop an application that requires this type of expertise and the spending of such expenditures prior to a grant's approval. This may hold true in spite of the AA program, as evidenced by the variable rates of participation across states and territories. 
Table 5. Perceived effectiveness of state or territory at performing HMA program-related activities.

\begin{tabular}{|c|c|c|c|c|c|}
\hline Questions & & & & & \\
\hline $\begin{array}{l}\text { Effectiveness of State or Territory } \\
\text { at Performing the Following } \\
\text { Activities }(n=42) \text {. }\end{array}$ & $\begin{array}{l}\text { \% Extremely } \\
\text { Effective }\end{array}$ & $\begin{array}{l}\text { \% Very } \\
\text { Effective }\end{array}$ & $\begin{array}{l}\text { Somewhat } \\
\text { Effective }\end{array}$ & $\begin{array}{l}\text { \% Slightly } \\
\text { Effective }\end{array}$ & $\begin{array}{l}\text { Effective at } \\
\text { All }\end{array}$ \\
\hline Conducting benefit-cost analyses. & 16.7 & 26.2 & 31.0 & 19.0 & 7.1 \\
\hline Providing engineering expertise. & 4.8 & 7.1 & 11.9 & 38.1 & 38.1 \\
\hline $\begin{array}{l}\text { Addressing environmental and } \\
\text { historic preservation issues. }\end{array}$ & 9.5 & 33.3 & 42.9 & 14.3 & 0 \\
\hline Addressing liability concerns. & 9.5 & 19.0 & 38.1 & 21.4 & 11.9 \\
\hline $\begin{array}{l}\text { Addressing maintenance } \\
\text { requirements. }\end{array}$ & 28.6 & 26.2 & 33.3 & 11.9 & 0 \\
\hline $\begin{array}{l}\text { Meeting period of performance } \\
\text { requirement. }\end{array}$ & 42.9 & 14.3 & 33.3 & 7.1 & 2.4 \\
\hline Managing multiple grant programs. & 52.4 & 35.7 & 11.9 & 0 & 0 \\
\hline $\begin{array}{l}\text { Coordinating with multiple state } \\
\text { agencies. }\end{array}$ & 47.6 & 40.5 & 11.9 & 0 & 0 \\
\hline Providing staff relative to workload. & 21.4 & 31.0 & 16.7 & 23.8 & 7.1 \\
\hline Retaining staff. & 26.2 & 19.0 & 26.2 & 16.7 & 11.9 \\
\hline $\begin{array}{l}\text { Transferring lessons gained by } \\
\text { previous employees. }\end{array}$ & 21.4 & 16.7 & 42.9 & 9.5 & 9.5 \\
\hline $\begin{array}{l}\text { Providing support to low capacity } \\
\text { communities to develop grant } \\
\text { applications. }\end{array}$ & 21.4 & 38.1 & 21.4 & 16.7 & 2.4 \\
\hline $\begin{array}{l}\text { Providing support to low capacity } \\
\text { communities to manage grants once } \\
\text { awarded. }\end{array}$ & 19.0 & 35.7 & 23.8 & 16.7 & 4.8 \\
\hline
\end{tabular}

Another technical skill associated with HMA grants administration involves maintaining an awareness of environmental protection and historic preservation rules and regulations and the application of this knowledge to ensure applications are compliant. This may entail, for instance, understanding the potential environmental impacts of varied projects and an understanding of how differing hazard mitigation measures affect the historic integrity of structures. The responses of SHMOs indicate that the nationwide efficacy of states and territories to assist local governments with this task is highly variable, to include a significant proportion of states and territories with insufficient capacity.

The ability of SHMOs to assist local governments with liability-related issues regarding HMA grants garnered the lowest affirmative response rate. Given that much of the liability-related issues are tied to a local government's legal authorities, this may have skewed the results as SHMOs or their agency's legal staff may be reluctant to provide this type of assistance.

The responses to this set of questions seem to align with an earlier observation that SHMOs appear more confident in their ability to process grant management paperwork and deliver administration guidance, while their perceived ability to address technical matters are more variable. For instance, when asked about the effectiveness of state and territorial officials to meet the period of performance requirement (i.e., the ability of states and territories to complete the implementation and closeout of local HMA grants in the time allowed by FEMA), only $2 \%$ of respondents said they were "not effective at all" and $43 \%$ stated that they were "extremely effective." Similarly, when SHMOs were asked about their perceived effectiveness in managing multiple grant programs, over half of the respondents (52\%) said they were "extremely effective," while $35 \%$ reported that they were "very effective" and $12 \%$ responded that they were "somewhat effective."

Past research shows that while state and territorial staffing levels are critically important when assessing capacity, responses proved to be highly variable, in large part because access to the management costs used to pay for grant management staff is tied to fluctuating post-disaster allocations 
of HMGP funding [19]. This research seems to support the survey findings, in that when asked about providing state and territorial staff relative to workload, $7 \%$ stated that their reported staffing levels were "not effective at all," 3\% reported they were "slightly effective," and 16\% stated that they were "somewhat effective." In total, this equates to that just over one quarter of those surveyed believe that their staffing levels are mediocre or poor. Slightly more than half of the SHMOs queried reported that their staffing levels were "very effective" (31\%) and "extremely effective" (21\%).

When asked about SHMOs' ability to retain staff over time, respondents expressed similarly divergent opinions. Thus, the ability to hire and maintain an adequate staffing level, coupled with a limited number of state and territorial personnel with the requisite technical expertise to assist local governments to develop HMA applications points to a serious problem related to the ability to maintain adequate numbers and types of employees. Understood collectively, this has the potential to span all capacity-building related questions.

SHMOs reported very high levels of effectiveness when it comes to coordinating with other state agencies, where $48 \%$ of respondents reported that they were "extremely effective" and $41 \%$ reported being "very effective." Thus, an important question merits further exploration, namely, how can states and territories better use these relationships to bolster HMA-specific grants' management capacity as reported by inadequate staffing levels and technical expertise? The high levels of reported coordination with other state and territorial agencies may imply that they consider coordinative activities covered through their state or territory hazard mitigation plan, which requires identifying state agency partners. However, the results also appear to suggest that states and territories may not be seeking a more direct involvement of these partners in HMA grants administration-related activities, which, similarly to what was discussed at the local level, implies that more attention should be paid to hazard mitigation governance.

For instance, the ability to transfer HMA lessons learned over time requires maintaining a continuity of knowledge across past, current, and future staff, and thus, there may be an association between perceived efficacy of lesson transfer and staffing. Yet when queried, 20\% of SHMOs reported that they were "not at all effective" or "slightly effective" in transferring lessons. The largest number of SHMOs (43\%) reported being "somewhat effective," while $16 \%$ and $21 \%$ reported being "very" or "extremely effective," respectively. A more detailed assessment of the interaction between staffing and the sharing of lessons merits further attention, to include interviews with SHMOs and other state and territorial agency officials to further unpack this relationship.

Oftentimes, those who stand to benefit from lessons the most are those with a limited capacity (and experience) required to undertake HMA grant management activities. The inherent challenges associated with these complex HMA programs are further magnified by a general lack of policy learning, in particular when applied to the acquisition of hazard-prone housing, which is among the most complex hazard mitigation grants to administer [20,46]. When SHMOs were asked about their perceived effectiveness in assisting low capacity communities develop HMA grants, the majority expressed a relatively high perception of their capabilities. When asked a question about the perceived effectiveness of their actions related to HMA grant implementation, responses were similar. Broader categorical questions are more subjective, and this may be reflected in the higher ranking of their perceived abilities when compared to more targeted questioning.

Respondents noted that specific technical aspects of grant management, such as providing engineering support or assisting with environmental reviews of projects, were less effective, perhaps highlighting their focus on more general tracking of grants as they are implemented versus a more hands-on approach associated with direct assistance with the varied details of developing grants at the local level. As noted in [25], the fluctuation in state staffing levels may lead states and territories to focus on grant management generalists versus the temporary (and permanent) hiring of technical experts, such as engineers and environmental specialists. 


\section{Conclusions, Recommendations, and Future Research}

This article sought to better understand the roles played by states and territories in assisting local governments to build the capacity required to develop and implement HMA grants. Emphasis was placed on understanding how states and territories undertook this effort as well as assessing SHMOs' opinions about their perceived level of effectiveness in building local HMA grant management capacity. The roles undertaken and the perceived state and territorial capacity to assist local governments to develop and implement HMA grants proved highly variable.

When SHMOs were asked about their perceived effectiveness in assisting local governments to build the capacity needed to develop and implement HMA grants, they reported high levels of competence, which contradicted SHMOs' responses tied to specific elements of the HMA grant management process. According to survey respondents, the capacity and perceived effectiveness of the delivery of technical sub-elements of HMA program administration, such as a benefit-cost analysis, environmental and historic review, and engineering assistance, proved less robust, particularly when compared to tasks such as meeting FEMA reporting requirements and the closing out of HMA grants. The ability of states and territories to bolster their engineering and environmental expertise is particularly important as the PDM program is replaced with BRIC, with its emphasis on gray and green infrastructure projects.

While FEMA-funded programs such as Public Administration by States and Advanced Assistance represent a well-intended attempt to rectify long-standing and well-documented problems at the state, territory, and local level regarding the slow nature of HMA project development and implementation, the programs appear to have been enacted prior to addressing more systemic problems, to include raising the overall level of capacity among states, territories, and local governments to administer HMA grants. Based on the survey findings, it appears that a more concerted effort should be enacted to tackle this problem as part of any strategy to encourage more states, territories, and local governments to assume additional responsibilities such as those promulgated under the PAS and AA programs.

Modest levels of participation in the AA program, which provides funding to assist in the development of HMA applications, suggests that this program may need to be modified to better reflect local needs and conditions. Prior to initiating major changes to the program, however, further research is needed to gain a greater understanding of why local governments chose not to participate, including those jurisdictions located in states and territories where SHMOs reported at least one AA applicant. Initial data drawn from the survey discussed in this article, including the small sample of states and territories where no local governments participated in the AA program, suggest that a general lack of awareness of the program and rules that may not address local needs have hindered participation. These findings need to be assessed more broadly in order to ascertain a better nation-wide understanding of this situation.

According to survey respondents, states and territories appear relatively well-equipped to address general HMA administrative duties, and those with discernable capabilities should be encouraged to pursue PAS designation, which relieves some of the administrative burden assumed by FEMA. However, low levels of participation in the PAS may be reflective of more systemic issues in the larger HMA grant management program. One way to make tangible changes that address an identified shortfall among survey respondents is to place a stronger emphasis on state and territory capacity-building initiatives focused on the technical aspects of HMA grant management, such as benefit-cost analyses, environmental reviews, and engineering-based skills.

This will require more than providing funding through FEMAs' episodically-delivered management cost program. It will necessitate an increased level of non-disaster-based federal funding to support and sustain an appropriate base level of state and territory-level staffing for both general grant management administrators and technical experts who are qualified to address shortfalls identified in this article and build capabilities that reflect local needs and conditions. In time, as state and territory HMA capacities are improved, to include developing greater skills in key aspects of HMA 
grant management (benefit-cost analysis, engineering and environmental/historic reviews), states and territories may agree to assume more of these responsibilities through PAS agreements.

As nation-wide capabilities improve, a team of representatives from PAS states and territories could deliver more targeted training and educational initiatives to other states and territories as part of inter-state and inter-territorial mutual aid agreements. Another possibility involves drawing from the expertise of university faculty and engagement specialists as well as regional organizations, and other agency partners identified in state hazard mitigation plans. Striking a balance between the provision of additional federal resources needed to strengthen state and territory HMA capacity while recognizing the importance of states and territories assuming a greater responsibility to assist local governments develop and implement HMA grants remains an ongoing challenge. While maintaining incentive-based programs such as PAS should be encouraged, it should be undertaken in tandem with a greater emphasis on pre-event, federally-supported efforts that strive to develop and sustain an enhanced level of state and territory HMA grant management capacity.

The findings described in this paper are both timely and concerning, given the key role that states and territories play in the vertical integration of federal HMA programs that are ultimately implemented at the local level. While this survey was conducted 20 years after the passage of the Disaster Mitigation Act of 2000, the results serve as an informative prelude to the implementation of BRIC, an ambitious new national hazard mitigation program. Even though some SHMOs reported high levels of perceived capacity and efficacy, many did not, and this should raise important questions. Addressing the long-standing problems associated with building and sustaining state and territorial capacity is a good place to start. Otherwise, we can expect uneven HMA grant management results to continue as FEMA begins to roll out the Building Resilient Infrastructure and Communities program and the United States continues to rely on hazard mitigation funding to assist jurisdictions adapt to a changing climate.

Author Contributions: Conceptualization, G.S.; Data curation, O.V.; Formal analysis, G.S.; Funding acquisition, G.S.; Software, O.V.; Supervision, G.S.; Writing-review \& editing, O.V. All authors have read and agreed to the published version of the manuscript.

Funding: This research received no external funding.

Acknowledgments: This article is based upon work supported by the U.S. Department of Homeland Security under Grant Award Number 2015-ST-061-ND0001-01. The views and conclusions contained herein are those of the authors and should not be interpreted as necessarily representing the official policies, either expressed or implied, of the U.S. Department of Homeland Security.

Conflicts of Interest: The authors declare no conflict of interest. The funder, the U.S. Department of Homeland Security, had no role in the design, execution, interpretation, or writing of the study. The Federal Emergency Management Agency did, however, assist in the development of the survey, but did not assist in the collection or interpretation of the resulting data, nor did they help write this article.

\section{References}

1. National Research Council of the National Academies. Facing Hazards and Disasters: Understanding Human Dimensions; The National Academy Press: Washington, DC, USA, 2006.

2. Intergovernmental Panel on Climate Change. Managing the Risks of Extreme Events and Disasters to Advance Climate Change Adaptation (SREX); A Special Report of Working Groups I and II of the Intergovernmental Panel on Climate Change; Cambridge University Press: New York, NY, USA, 2012.

3. Union of Concerned Scientists. Underwater: Rising Seas, Chronic Floods, and the Implications for US Coastal Real-Estate; Union of Concerned Scientists: Cambridge, MA, USA, 2018.

4. National Oceanic and Atmospheric Administration, National Centers for Environmental Information (NCEI). U.S. Billion-Dollar Weather and Climate Disasters. 2018. Available online: https://www.ncdc.noaa.gov/ billions/ (accessed on 18 November 2020).

5. National Oceanic and Atmospheric Administration. Billion-Dollar Weather and Climate Disasters: Overview. National Centers for Environmental Information. 2020. Available online: https:/www.ncdc.noaa.gov/billions/ (accessed on 18 November 2020). 
6. FEMA. Hazard Mitigation Assistance Grants. 2020. Available online: https://www.fema.gov/grants/ mitigation (accessed on 18 November 2020).

7. Godschalk, D.R. Urban hazard mitigation: Creating resilient cities. Nat. Hazards Rev. 2003, 4, $136-142$. [CrossRef]

8. Cigler, B.A. U.S. Floods: The Necessity of Mitigation. State Local Gov. Rev. 2017, 49, 127-139. [CrossRef]

9. FEMA. Hazard Mitigation Assistance Guidance; Hazard Mitigation Grant Program, Pre-Disaster Mitigation Program, and Flood Mitigation Assistance Program; FEMA: Washington, DC, USA, 2015.

10. Godschalk, D.R.; Beatley, T.; Berke, P.; Brower, D.; Kaiser, E. Natural Hazard Mitigation: Recasting Disaster Policy and Planning; Island Press: Washington, DC, USA, 1999.

11. Siders, A. Managed Coastal Retreat: A Legal Framework on Shifting Development Away from Vulnerable Areas. Columbia Public Law Res. Pap. 2013. [CrossRef]

12. Bukvic, A.; Borate, A. Developing coastal relocation policy: Lessons learned from the FEMA Hazard Mitigation Grant Program. Environ. Hazards 2020. [CrossRef]

13. Miyuki, H.; Field, C.B.; Mach, K.J. Managed retreat as a response to natural hazard risk. Nat. Clim. Chang. 2017, 7, 364-370.

14. Godschalk, D.R.; Rose, A.; Mittler, E.; Porter, K.; West, C.T. Estimating the value of foresight: Aggregate analysis of natural hazard mitigation benefits and costs. J. Environ. Plan. Manag. 2009, 52, 739-756. [CrossRef]

15. United States Government Accountability Office. Major Management Challenges and Program Risks: Federal Emergency Management Agency; GAO-03-113; United States Government Accountability Office: Washington, DC, USA, 2003.

16. United States Governmental Accountability Office. Report to the Ranking Member, Committee on Financial Services, House of Representatives. Natural Hazard Mitigation: Various Mitigation Efforts Exist, but Federal Efforts Do Not Provide a Comprehensive Strategic Framework; GAO 07-403; United States Governmental Accountability Office: Washington, DC, USA, 2007.

17. Congressional Research Service. FEMA's Hazard Mitigation Grant Program: Overview and Issues; Congressional Research Service: Washington, DC, USA, 2009.

18. McCarthy, F.X.; Keegan, N. FEMA's Pre-Disaster Mitigation Program: Overview and Issues; Congressional Research Service: Washington, DC, USA, 2009.

19. United States Governmental Accountability Office. Hurricane Sandy: An Investment Strategy Could Help the Federal Government Enhance National Resilience for Future Disasters; GAO-15-515; United States Governmental Accountability Office: Washington, DC, USA, 2015.

20. Binder, S.B.; Greer, A.; Zavar, E. Home buyouts: A tool for mitigation or recovery? Disaster Prev. Manag. Int. J. 2020. [CrossRef]

21. Greer, A.; Binder, S.B. A historical assessment of home buyout policy: Are we learning or just failing? Hous. Policy Debate 2017, 27, 372-392. [CrossRef]

22. Weber, A.; Moore, R. Going Under: Long Wait Times for Post-Flood Buyouts Leave Homeowners Underwater; Natural Resources Defense Council: Washington, DC, USA, 2019; Available online: https://www.nrdc.org/ sites/default/files/going-under-post-flood-buyouts-report.pdf (accessed on 29 October 2020).

23. Mach, K.J.; Kraan, C.M.; Hino, M.; Siders, A.R.; Johnson, E.M.; Field, C.B. Managed retreat through voluntary buyouts of flood-prone properties. Sci. Adv. 2019, 5, 1-9. [CrossRef] [PubMed]

24. Elliott, J.R.; Brown, P.L.; Loughran, K. Racial inequities in the federal buyout of flood-prone homes: A nationwide assessment of environmental adaptation. Socius 2020, 6, 1-15. [CrossRef]

25. Smith, G.; Lyles, W.; Berke, P. The Role of the State in Building Local Capacity and Commitment for Hazard Mitigation Planning. Int. J. Mass Emergencies Disasters 2013, 31, 178-203.

26. Berke, P.; Lyles, W.; Smith, G. Planning for Resiliency: Evaluation of State Hazard Mitigation Plans under the Disaster Mitigation Act. Nat. Hazards Rev. 2012, 13, 139-149. [CrossRef]

27. Sapat, A. The Intergovernmental Dimensions of Natural Disaster and Crisis Management in the United States. In Handbook of Crisis and Emergency Management; Farazmand, A., Ed.; Marcel Dekker: New York, NY, USA, 2001; pp. 339-356.

28. Smith, G.; Sandler, D.; Goralnik, M. Assessing State Policy Linking Disaster Recovery, Smart Growth and Resilience in Vermont Following Tropical Storm Irene. Vt. J. Environ. Law 2013, 15, 67-102. [CrossRef] 
29. Smith, G. The Role of States in Disaster Recovery: An Analysis of Engagement, Collaboration, and Capacity Building. In The Routledge Handbook of Urban Disaster Resilience: Integrating Mitigation, Preparedness, and Recovery Planning; Lindell, M.L., Ed.; Routledge Press: New York, NY, USA, 2020; pp. 352-377.

30. PUBLIC LAW 106-390-OCT. 30, 2000. 114 STAT. 1553. Disaster Mitigation Act of 2000; U.S. Government Publishing Office: Washington, DC, USA, 2000.

31. Smith, G. Creating Disaster Resilient Communities: A New Hazards Risk Management Framework. In Hazards Analysis: Reducing the Impact of Disasters, 2nd ed.; Pine, J., Ed.; CRC Press: Boca Raton, FL, USA, 2015; pp. 281-308.

32. Lyles, W.; Berke, P.; Smith, G. A Comparison of Local Hazard Mitigation Plan Quality in Six States, USA. Landsc. Urban Plan. 2014, 122, 89-99. [CrossRef]

33. Frazier, T.G.; Walker, M.H.; Kumari, A.; Thompson, C.M. Opportunities and constraints to hazard mitigation planning. Appl. Geogr. 2013, 40, 52-60. [CrossRef]

34. Lyles, W.; Berke, P.; Smith, G. Do Planners Matter? Examining Factors Driving Incorporation of Land Use Approaches into Hazard Mitigation Plans. J. Environ. Plan. Manag. 2014, 57, 792-811. [CrossRef]

35. Smith, G. Planning for Post-Disaster Recovery: A Review of the United States Disaster Assistance Framework; Island Press: Washington, DC, USA, 2011.

36. FEMA. Disaster Recovery Act (DRRA) Annual Report; FEMA: Washington, DC, USA, 2019.

37. Smith, G.; Vila, O.; Caverly, G. A National Evaluation of State Roles in Hazard Mitigation: Building Local Capacity to Implement FEMA Hazard Mitigation Assistance Grants; DesignSafe-CI: Miami, FL, USA, 2020. [CrossRef]

38. Dillman, D.A. Mail and Telephone Survey: The Total Design Method; John Wiley \& Sons: New York, NY, USA, 1978.

39. United States Governmental Accountability Office. Disaster Assistance: Opportunities to Improve Cost-Effectiveness Determinations for Mitigation Grants; Report to Congressional Committees; GAO/RCED-99-23; United States Governmental Accountability Office: Washington, DC, USA, 1999.

40. Frequently Asked Questions: Hazard Mitigation Grant Program (HMGP) Management Costs. FEMA. Available online: https://www.fema.gov/media-library-data/158525815559645b0c16a767271ab73da438bda5c82c5/management-cost-faq_3-23-2020.pdf (accessed on 28 October 2020).

41. Klein, N. The Shock Doctrine: The Rise of Disaster Capitalism; Metropolitan Book: New York, NY, USA, 2007.

42. Jerolleman, A. The Privatization of Hazard Mitigation: A Case Study of the Creation and Implementation of a Federal Program. Ph.D. Thesis, University of New Orleans, New Orleans, LA, USA, 2013.

43. United States Governmental Accountability Office. Report to Congressional Requesters. National Preparedness: Additional Actions Needed to Address Gaps in the Nation's Emergency Management Capabilities; GAO-20-29; United States Governmental Accountability Office: Washington, DC, USA, 2020.

44. Thomas, E.A.; Jerolleman, A.; Turner, T.L.; Punchard, D.; Bowen, S.K. Planning and Building Livable, Safe E Sustainable Communities: The Patchwork Quilt Approach; Natural Hazard Mitigation Association: Boston, MA, USA, 2013.

45. Notice of Funding Opportunity for Hazard Mitigation Assistance Grants. FEMA. Available online: https://www.fema.gov/sites/default/files/2020-09/fema_bric_fy-2020_nofo_fact-sheet.pdf (accessed on 9 September 2020).

46. Gavin, S. Applying Hurricane Recovery Lessons in the U.S. to Climate Change Adaptation: Hurricanes Fran and Floyd in North Carolina, USA. In Adapting to Climate Change: Lessons from Natural Hazards Planning; Glavovic, B., Smith, G., Eds.; Springer: New York, NY, USA, 2014; pp. 193-229.

Publisher's Note: MDPI stays neutral with regard to jurisdictional claims in published maps and institutional affiliations.

(C) 2020 by the authors. Licensee MDPI, Basel, Switzerland. This article is an open access article distributed under the terms and conditions of the Creative Commons Attribution (CC BY) license (http://creativecommons.org/licenses/by/4.0/). 